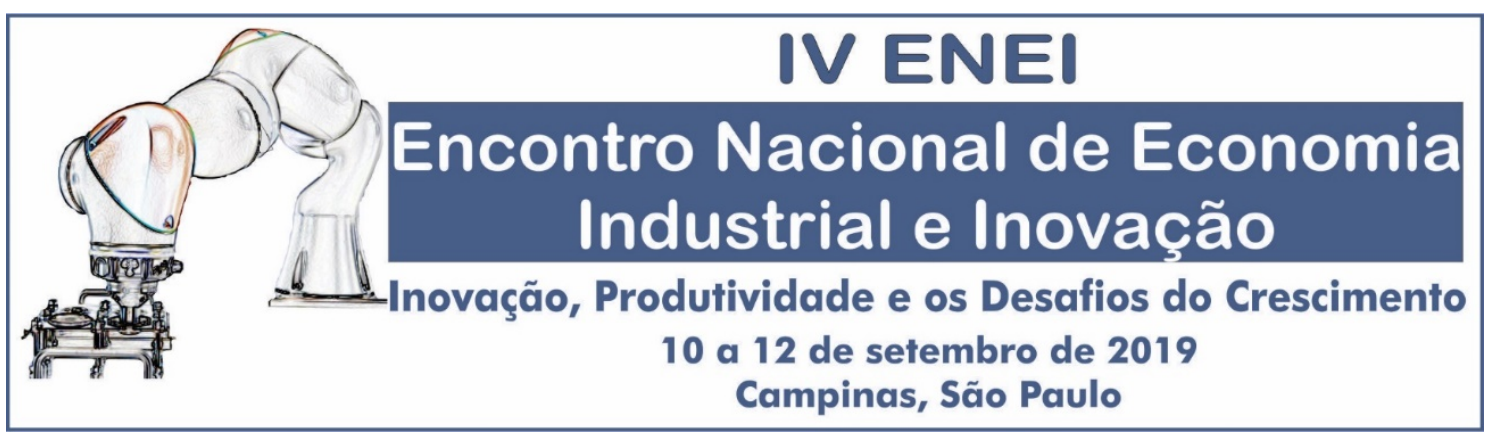

\title{
Industrialização e desindustrialização brasileira pela ótica do emprego
}

\author{
Paulo César Morceiro (FEA-USP) ${ }^{1}$
}

Área ABEIN: 2.3 - Salários, emprego e divisão internacional do trabalho

Resumo. No Brasil, os diagnósticos sobre a industrialização concentram-se na parcela da indústria de transformação no PIB, e são escassos os trabalhos que avaliam o tema sob a ótica do emprego. No entanto, tal diagnóstico não é negligenciado nos países que estão em estágio de desenvolvimento superior ao brasileiro. Este estudo propõe realizar uma avaliação da (des)industrialização brasileira pela ótica do emprego ao longo de oito décadas. Para tanto, serão apresentadas informações inéditas para o debate de desindustrialização a partir de várias bases de dados. $\mathrm{O}$ artigo formula algumas hipóteses sobre a baixa absorção de mão-de-obra pela industrialização brasileira em comparação com os países pioneiros na industrialização. Os resultados iniciais evidenciam que a desindustrialização brasileira foi prematura não apenas quanto ao nível de renda per capita, mas também em relação ao estágio demográfico e quanto à composição setorial das ocupações.

Palavra-chaves: Industrialização; Emprego manufatureiro; Mudança estrutural.

Abstract. In Brazil, industrialization diagnoses are concentrated in the manufacturing sector share in GDP, and there are few studies that evaluate the theme from the employment perspective. However, such a diagnosis is not neglected in countries that are at a higher development stage than Brazil. This study evaluates Brazilian (de)industrialization through the employment perspective over eight decades. This study collected data from various sources of information. It presents unprecedented information for the Brazilian debate on deindustrialization from the employment perspective. The article formulates some hypotheses about the low labor absorption by Brazilian industrialization in comparison with the pioneer industrialization countries. The initial results show that Brazilian deindustrialization was premature not only regarding the per capita income level but also in relation to the demographic stage and the sectoral composition of occupations.

Keywords: Industrialization; Manufacturing employment; Structural change.

Classificação JEL: L16; J21; O11.

\footnotetext{
${ }^{1}$ Doutor em Economia pela FEA-USP. E-mail: paulo.morceiro@gmail.com. O autor agradece a Milene Simone Tessarin pelas sugestões a uma versão anterior, isentando-a de erros e omissões remanescentes.
} 


\section{Introdução}

As avaliações da desindustrialização brasileira concentram-se no peso da indústria de transformação no Produto Interno Bruto (PIB), conforme amplo levantamento bibliográfico realizado por Morceiro (2012). No entanto, a maioria dos diagnósticos internacionais de desindustrialização concentra sua análise na evolução do emprego manufatureiro no emprego total ao invés da parcela manufatureira no PIB (MORCEIRO, 2012; TREGENNA, 2016). No Brasil, as avaliações pela ótica do emprego são escassas devido à ausência de dados com longa cobertura temporal.

Este texto apresenta dados inéditos que permitem avaliar tanto a industrialização quanto à desindustrialização brasileira pela ótica do emprego, dessa forma, ele contribui com a literatura especializada. Adicionalmente, ele formula algumas hipóteses para a baixa absorção de mão de obra pela indústria brasileira no período de industrialização e aponta outras formas - além da renda per capita - para qualificar a desindustrialização brasileira como prematura.

Julgamos que o tema é muito relevante para a discussão brasileira sobre (des)industrialização e desenvolvimento. $\mathrm{O}$ artigo apresenta informações inéditas que merecem ser mais bem exploradas pela literatura.

\section{Industrialização e desindustrialização de longo prazo pelo emprego total}

A parcela do emprego manufatureiro no total tem diminuído bastante nos países desenvolvidos, mas aumentado naqueles em desenvolvimento (HARAGUCHI; CHENG; SMEETS, 2017), de forma que o resultado agregado para a economia mundial é uma estabilidade da participação do emprego na indústria desde 1970 até 2010 (FELIPE; MEHTA, 2016). ${ }^{2}$

No Brasil, os diagnósticos sobre a industrialização concentram-se na parcela da indústria de transformação no PIB, principalmente porque inexistem séries contínuas de emprego manufatureiro no período da industrialização brasileira. Para suprir essa carência, o Gráfico 1 reúne informações de emprego total - formal e informal - de distintas fontes.

Para 1940, 1950, 1960, 1970 e 1980 há informações dos Censos que foram padronizadas pelo IBGE (2006) na estrutura de divulgação da Pesquisa Nacional por Amostra de Domicílios (PNAD), por isso os dados dessas décadas são comparáveis com a série desta Pesquisa. A PNAD é a série mais longa, com dados para 1973 e 1976-2015, exceto para os anos de 1991, 1994, 2000 e 2010. Adicionalmente, empregou-se as séries dos três sistemas de contas nacionais disponíveis a partir de 1990, que têm elevada aderência com a série da PNAD, assim como os dados das matrizes de insumo-produto desde 1970.

As análises a seguir concentram-se na série da PNAD e dos Censos compatibilizados com a estrutura da PNAD - doravante, série Censo-PNAD, destacada em cor mais forte no Gráfico 1 a seguir.

\footnotetext{
${ }^{2}$ Morceiro e Tessarin (2019) também verificaram que há uma estabilidade da participação da manufatura no PIB da economia mundial para as últimas cinco décadas a partir de informações padronizadas pelas Nações Unidas.
} 
Gráfico 1 - Parcela do emprego da indústria de transformação no total, 1940/ 1950/ 1960/ 1970/ 1973/ 1975-2016

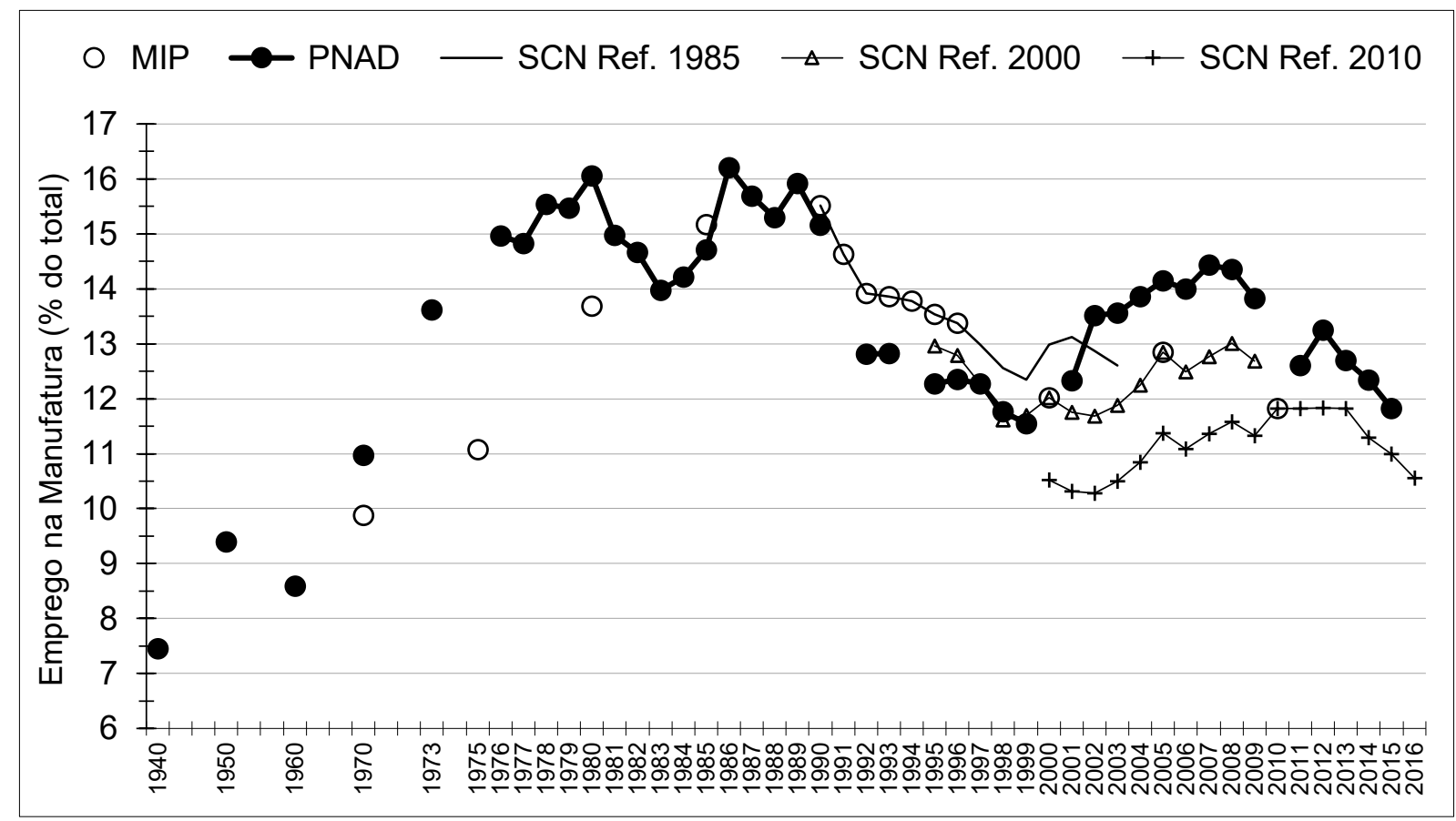

Nota: Dados do Censo padronizados na estrutura setorial da PNAD pelo IBGE (2006) para 1940, 1950, 1960, 1970 e 1980.

Fonte: PNAD (várias edições), Matriz de Insumo-Produto (várias edições) e IBGE (2004, 2006, 2011, 2018). Elaborado pelo autor.

No período da industrialização brasileira, coberto no Gráfico 1, a parcela do emprego manufatureiro no emprego total elevou-se de 7,4\% para 16,1\%, entre 1940 e 1980. Em números absolutos, aumentou de 1,10 milhão para 6,94 milhões de ocupações no mesmo período. Entre 1981 e 1983, a parcela do emprego diminuiu devido à crise do início da década de 1980, mas recuperou o nível de 1980 já em 1986. De 1987 até 1999, há uma tendência declinante, sendo o período mais intenso da desindustrialização brasileira pelo emprego. Entre 2000 e 2008, a parcela do emprego manufatureiro aumentou um pouco, mas essa recuperação foi insuficiente para retornar ao pico da década de 1980 (ver Gráfico 1). Desde 2009, a parcela do emprego manufatureiro vem caindo.

A série do emprego exibida no Gráfico 1 teve pico num nível mais baixo que a parcela manufatureira no PIB. A parcela da indústria de transformação alcançou o máximo de 27,3\% do PIB em 1986 (MORCEIRO, 2019, p. 24; Gráfico 2) e a parcela do emprego atingiu o pico de aproximadamente 16\% no mesmo ano (Gráfico 1) e também em 1980 (Gráfico 3). 
Gráfico 2 - Participação setorial no PIB, a preços básicos e correntes, Brasil, 1948-2018

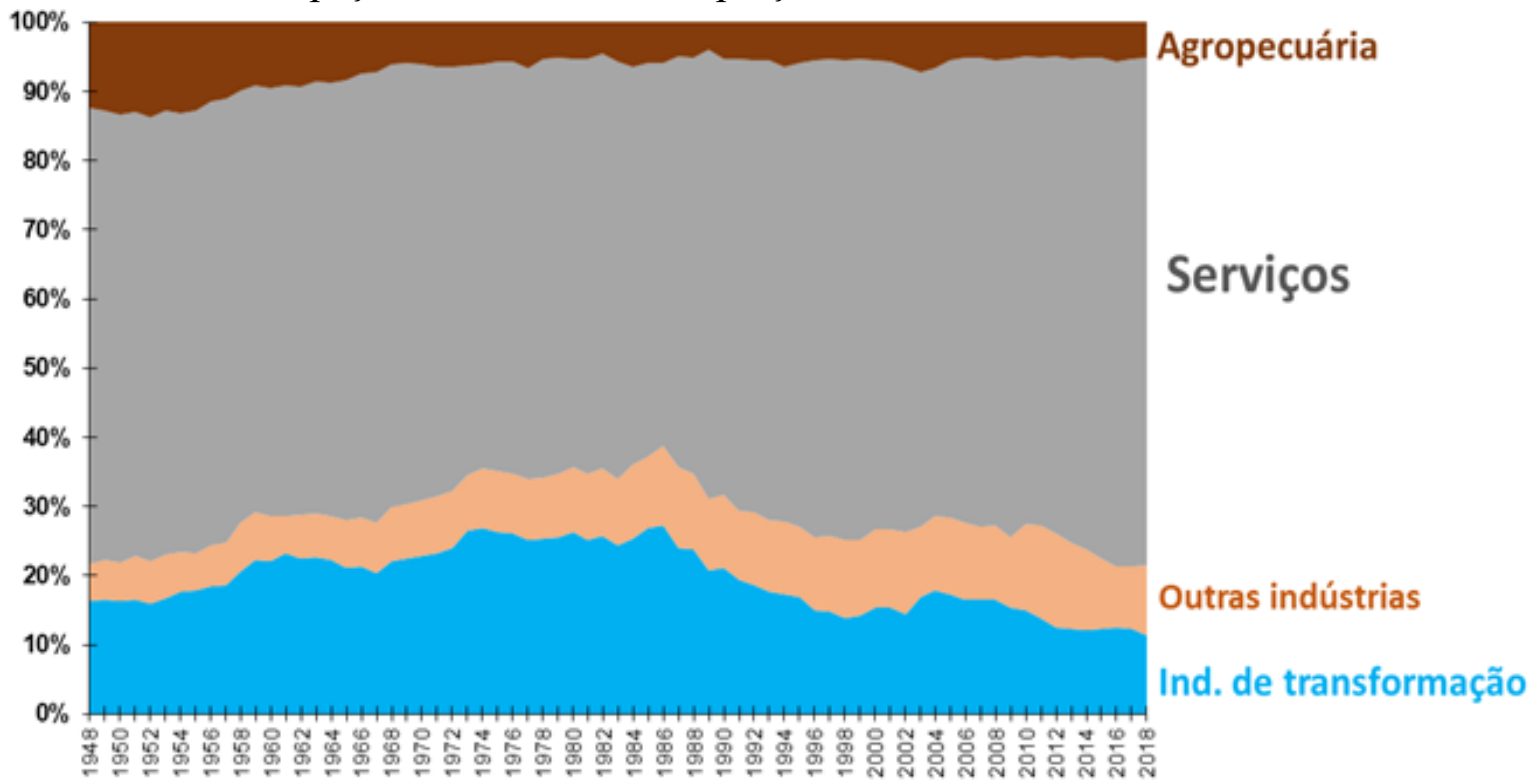

Nota: Séries setoriais ajustadas e compatíveis com o atual Sistema de Contas Nacionais Referência 2010 do IBGE. Foi realizado um ajuste para eliminar os problemas causados pelo dummy financeiro e pelas quebras seriais que surgiram após as mudanças metodológicas implementadas pelo IBGE.

Fonte: Morceiro (2019).

Sendo assim, os Gráficos 2 e 3 mostram que o pico da industrialização brasileira ocorreu na mesma época tanto pelo PIB quanto pelo emprego, porém em níveis diferentes proporcionalmente à economia total. Em termos de PIB, a parcela manufatureira no total do Brasil aproximou-se dos países industriais líderes (Estados Unidos, Japão e Alemanha), nos quais a manufatura alcançou cerca de $30 \%$ do PIB no pico da industrialização. No entanto, o Gráfico 2 revela que a industrialização brasileira absorveu pouca mão de obra comparativamente aos mesmos países industriais líderes. ${ }^{3}$

$\mathrm{Na}$ verdade, quando o Brasil começou a se desindustrializar na década de 1980 cerca de um terço da força de trabalho empregada ainda se encontrava na agropecuária (Gráfico 3), ou seja, ainda havia bastante mão de obra a ser transferida do setor atrasado para o setor moderno a la Lewis (1954).

O Gráfico 3 revela outro traço distintivo do desenvolvimento brasileiro: o emprego praticamente "pulou" a fase industrial ao se deslocar direto da agropecuária para os serviços.

\footnotetext{
${ }^{3} \mathrm{O}$ pico da parcela do emprego manufatureiro brasileiro de aproximadamente $16 \%$ em 1980 (e novamente em 1986), exibidos no Gráfico 1 , foi muito inferior àquele verificado nos países de industrialização madura e atualmente desenvolvidos. A parcela do emprego manufatureiro no emprego total alcançou 35,8\% na Alemanha em 1970; 32,3\% nos Estados Unidos em 1948; 32,2\% no Reino Unido em 1971; 29,1\% na Itália em 1980; 28,7\% na Coreia do Sul em 1989; 26,3\% no Japão em 1973; 25,8\% na França em 1973. Nos outros dois maiores países da América Latina, a parcela do emprego alcançou 27,7\% na Argentina em 1958 e 20,0\% no México em 1990. Os dados mencionados provêm da U.S Bureau of Economic Analysis, OECDSTAN Database (2018) e GGDC 10-Sector Database de Timmer, De Vries e De Vries (2016).
} 
Gráfico 3 - Distribuição setorial do emprego, Brasil, 1940 a 2015 (em \%)

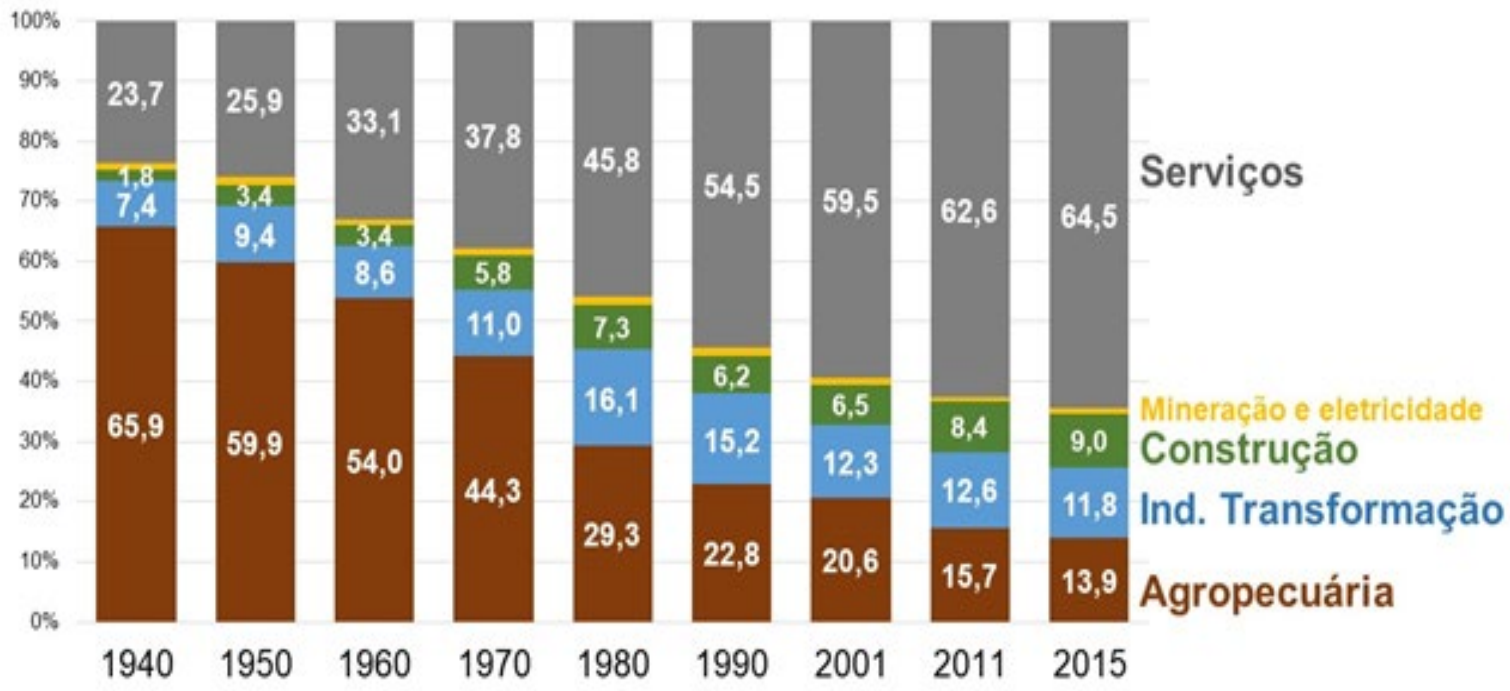

Fonte: Censo e PNAD. Elaborado pelo autor.

A partir da exposição acima fica evidente que a fase de industrialização do Brasil absorveu mão de obra em uma proporção muito menor que os países industriais líderes. As próximas seções buscam investigar o porquê disso.

\section{Baixa absorção de mão de obra pela industrialização brasileira}

A capacidade de absorver mão de obra foi o calcanhar de Aquiles da industrialização dos países em desenvolvimento, sobretudo do Brasil. Como atestam Baer e Hervé (1966, p. 89, tradução nossa)

Para toda a América Latina a taxa de crescimento anual da população urbana no período de $1945-60$ foi de $4,3 \%$, a taxa de crescimento da população economicamente ativa do setor não-agrícola foi de 3,9\% e a taxa de crescimento do emprego na manufatura foi de $2,8 \%$. No Brasil, nos anos de 1950-1960, enquanto a população urbana cresceu 5,4\% a taxa de crescimento do emprego na manufatura foi apenas 2,6\%. Em outras partes do mundo a situação foi semelhante.

Baer, ao fazer uma avaliação da industrialização no Brasil, destaca que "[o] desempenho do setor industrial como empregador tem sido decepcionante" (BAER, 1985, p. 310) e o "(...) o maior problema tem sido sua incapacidade de criar número suficiente de empregos que ajudasse a absorver uma população urbana em rápida expansão, resultado de uma alta taxa geral de crescimento demográfico e um processo intenso de migração rural-urbana." (BAER, 1985, p. 447). Também por isso, o autor afirmou que houve um semi-desenvolvimento e uma semi-industrialização no Brasil (BAER, 1985, cap. 19).

Neste estudo, são levantadas cinco hipóteses da baixa absorção de mão de obra pela industrialização brasileira. Primeira hipótese, o Brasil é um país de industrialização tardia, que se industrializou numa época em que as tecnologias e os processos produtivos tiveram maior mecanização relativamente aos países de industrialização pioneira (BAER; HERVÉ, 1966), embora a Coreia do Sul tenha se industrializado na mesma época que o 
Brasil e sua parcela de emprego manufatureiro tenha sido, no pico, 12,5 p.p. superior à da brasileira.

Segunda, o Brasil não completou a última etapa do seu processo de industrialização, que é puxado pelas exportações, sobretudo de bens de capital e produtos de elevada intensidade tecnológica, conforme os estágios da industrialização mencionados por Kaldor (1967). Nos países desenvolvidos, as exportações foram fonte de demanda relevante para o setor industrial, mas no Brasil elas tiveram um papel marginal devido à fraca inserção deste país nos mercados internacionais de produtos manufaturados.

A terceira refere-se a curta duração no pico da participação do emprego manufatureiro no Brasil. $^{4} \mathrm{Na}$ verdade, o período de industrialização brasileiro contabilizado em décadas - foi relativamente curto comparativamente ao dos países desenvolvidos que iniciaram a industrialização ainda no século XVIII ou no início do século XIX.

Quarta, colaborando com as duas últimas, a industrialização brasileira foi parcial e não atingiu a maturidade verificada nos países de industrialização avançada. A industrialização brasileira teve êxito na implantação do parque industrial do complexo metal-mecânico-químico e das indústrias de bens de consumo não-duráveis, mas não nos setores da terceira revolução industrial relacionados à indústria de informática e de produtos eletrônicos que foram muito relevantes para a industrialização dos países asiáticos.

Quinta, grande parte do processo de industrialização brasileiro concentrou-se em 1950-1980, período de elevado crescimento populacional, dessa forma, as tecnologias deste período foram poupadoras de mão de obra (hipótese 1) e absorveram uma pequena parcela da expansão populacional.

\section{A demografia e a composição setorial na desindustrialização brasileira}

A hipótese demográfica joga um papel relevante na desindustrialização brasileira. O Brasil começou a se desindustrializar com uma taxa de crescimento demográfica elevada comparativamente à fase de desindustrialização dos países desenvolvidos. No início dos anos 1980, a PIA e a PEA cresceram acima de $2,5 \%$ a.a.; e ainda no início dos anos 2000, a PIA superava marginalmente a taxa de 2,0\% a.a. ${ }^{5}$ Durante a desindustrialização ocorreu uma transição demográfica significativa em que a taxa de atividade (razão entre a PIA e a população residente) aumentou 11,3 p.p., de 57,6\% para $68,9 \%$, entre 1980 e 2015, no Brasil.

Como 34,4\% da força de trabalho estava empregada na agropecuária (Matriz de Insumo-Produto de 1980; ou Gráfico 3 a partir de outra fonte), ainda existia oferta ilimitada de mão de obra à la Lewis (1954) a ser transferida para os setores modernos, que na época correspondia basicamente à indústria de transformação. Devido à

\footnotetext{
${ }^{4}$ Por exemplo, veja o caso dos Estados Unidos, país continental e populoso como Brasil. Nos Estados Unidos, entre 1929 e 1974, a parcela do emprego manufatureiro oscilou entre $25,0 \%$ e 32,4\%, e sempre foi superior a $28 \%$ em 2/3 desse período de 45 anos (dados do U.S Bureau of Economic Analysis).

5 A PIA dos países que formam o G-7 (Estados Unidos, Japão, Alemanha, Reino Unido, França, Itália e Canadá) cresceu 1,05\% a.a. entre 1965 e 1980, período em que esses eles começaram a se desindustrializar, conforme cálculos do autor a partir da base de dados do Banco Mundial.
} 
mecanização da produção agrícola, o êxodo rural ${ }^{6}$ continuou intenso nas décadas de 1980 e 1990, contribuindo para aumentar a PEA. Contudo, em 2016, ainda havia 13,1\% da força de trabalho ocupada no setor agropecuário (IBGE, 2018). A título de comparação, nos Estados Unidos apenas $1,8 \%$ da força de trabalho estava empregada no setor agropecuário e $27,6 \%$ no setor manufatureiro em 1969, ano em que começaram a se desindustrializar pela ótica do emprego; já em 2015, apenas 0,9\% das ocupações estavam na agropecuária, conforme dados da U.S Bureau of Economic Analysis.

Dessa maneira, o Brasil começou a se desindustrializar também prematuramente quanto ao estágio demográfico e à composição setorial das ocupações, além do baixo nível da renda per capita frequentemente mencionado pela literatura. Com isso, o país não seguiu a cartilha básica das teorias do desenvolvimento: aumentar a produtividade e a renda per capita por meio da mudança estrutural intersetorial, que basicamente consiste em transferir mão de obra dos setores de baixa produtividade (agropecuária) para os setores de elevada produtividade (manufatura e alguns setores de serviços).

Assim, nas décadas de 1980 e 1990, o Brasil desperdiçou uma excelente oportunidade de escapar da armadilha da renda média via mudança estrutural intersetorial. Certamente, as raízes da desindustrialização prematura brasileira são deste período.

Ainda na década de 1990 houve retração de 16\% do emprego manufatureiro equivalente a diminuição de 1,5 milhão de postos de trabalho -, segundo as Contas Nacionais. Assim, o problema da mão de obra agravou-se à medida que a PEA aumentava e continuava o êxodo rural. A consequência disso foi o aumento do subemprego e empregos precários (por ex., camelôs) e moradias irregulares nas áreas urbanas. Setorialmente, aumentou o emprego nos setores de serviços com elevada informalidade e baixíssima produtividade (como serviços domésticos, serviços pessoais e prestados às famílias, e comércio).

\section{Desindustrialização pelo emprego formalizado}

A parcela do emprego industrial formal no total exibidos no Gráfico 4, disponíveis anualmente desde de 1985, confirmam os períodos de desindustrialização intensa (19871999 e 2009-atual) observados na série PNAD do Gráfico 1.

Os empregos formais da indústria de transformação devem espelhar bem os empregos totais (formais e informais), pois a maioria das ocupações industriais é formalizada.

\footnotetext{
${ }^{6}$ Em 1980, 1991, 2000 e 2015 respectivamente, 32,3\%, 24,5\%, 18,8\% e 15,3\% da população residiam em áreas rurais, conforme informações dos Censos Demográficos e da PNAD para o último ano.
} 
Gráfico 4 - Empregos formais na indústria de transformação brasileira, 1985 a 2018

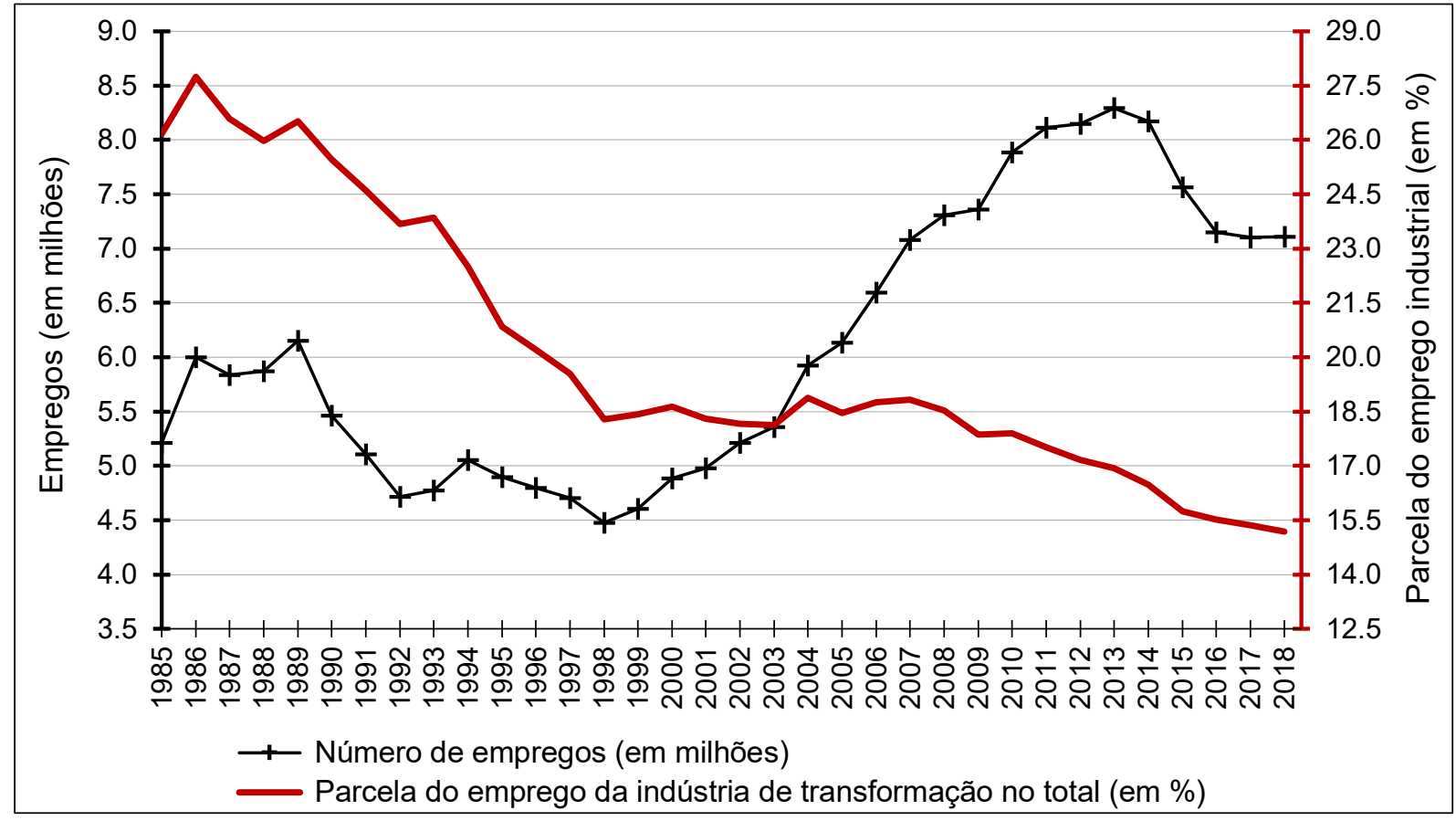

Fonte: RAIS e CAGED / Ministério do Trabalho e Emprego. Elaborado pelo autor.

Em números absolutos, houve queda dos empregos manufatureiros formais a partir de 1989 até 1998 e no quadriênio 2014-2017 (eixo esquerdo do Gráfico 1). Note que só em 2005, o volume de empregos formais da indústria de transformação atingiu o nível obtido em 1990.

\section{Considerações finais}

Este texto apresenta dados inéditos do emprego manufatureiro para o período mais relevante da industrialização brasileira. As evidências empíricas revelaram que a industrialização brasileira absorveu pouca mão de obra comparativamente aos países de industrialização pioneira, como os Estados Unidos, Japão e Alemanha. A partir desse diagnóstico, cinco hipóteses da baixa absorção de mão de obra foram levantadas, sendo que três delas destacam que a industrialização brasileira foi interrompida e teve curta duração; dessa forma, não atingiu a maturidade industrial verificada nos países desenvolvidos. Para corroborar essa afirmação, foram apresentados dados inéditos da participação dos principais macro-setores no emprego total da economia que deixam bem claro que o emprego "pulou" a fase industrial, isto é, a mudança estrutural ocorreu majoritariamente a partir do deslocamento direto do emprego agropecuário para o setor de serviços.

Com isso, argumenta-se que a desindustrialização brasileira foi prematura não apenas quanto ao nível de renda per capita. Verificou-se que o Brasil começou a se desindustrializar também prematuramente quanto ao estágio demográfico e à composição setorial das ocupações. Em 1980, no início da desindustrialização, a taxa de crescimento da PEA era elevada e um terço da força de trabalho encontrava-se no setor agropecuário, evidências que revelam que ainda existia oferta ilimitada de mão de obra à la Lewis a ser transferida e absorvida pela industrialização. Portanto, o nível da renda per capita não pode ser o único critério utilizado para qualificar a desindustrialização de um país. 
Também vale destacar que a desindustrialização pelo emprego apresentou menor variabilidade e intensidade que a desindustrialização mensurada pelo PIB.

\section{Referências}

BAER, W. Industrialização e o desenvolvimento econômico do Brasil. 6. ed. Rio de Janeiro: FGV, 1985.

BAER, W.; HERVÉ, M. E. A. Employment and industrialization in developing countries. The Quarterly Journal of Economics, v. 80, n. 1, p. 88-107, 1966.

FELIPE, J.; MEHTA, A. Deindustrialization? A global perspective. Economics Letters, v. 149, p. 148-151, 2016.

HARAGUCHI, N.; CHENG, C. F. C.; SMEETS, E. The importance of manufacturing in economic development: has this changed? World Development, v. 93, p. 293-315, 2017.

IBGE - INSTITUTO BRASILEIRO DE GEOGRAFIA E ESTATÍSTICA. Sistema de contas nacionais: Brasil: 2003. Rio de Janeiro: IBGE, 2004.

IBGE. Estatísticas do século XX. Rio de Janeiro: IBGE, 2006.

IBGE. Sistema de contas nacionais: Brasil: 2005-2009. Rio de Janeiro: IBGE, 2011.

IBGE. Sistema de contas nacionais: Brasil 2016. Rio de Janeiro: IBGE, 2018.

KALDOR, N. Problems of Industrialization in Underdeveloped Countries. Ithaca: Cornell University Press, 1967.

LEWIS, W. A. Economic development with unlimited supplies of labour. The Manchester School, v. 22, n. 2, p. 139-191, 1954.

MORCEIRO, P. C. Desindustrialização na economia brasileira no período 20002011: abordagens e indicadores. São Paulo: Cultura Acadêmica, 2012.

MORCEIRO, P. C. Influência metodológica na desindustrialização brasileira e correções na composição setorial do PIB: TD Nereus 02-2019. São Paulo: Núcleo de Economia Regional e Urbana da USP, 2019.

MORCEIRO, P. C.; TESSARIN, M. S. Desenvolvimento industrial em perspectiva internacional comparada. São Paulo: Instituto de Estudos para o Desenvolvimento Industrial (IEDI), 2019.

OECD-STAN DATABASE. Database for Structural Analysis - STAN (ISIC Rev. 4, SNA08). Paris: OECD, 2018. Disponível em: <http://oe.cd/stan>.

TIMMER, M.; DE VRIES, G. J.; DE VRIES, K. Patterns of structural change in developing countries. In: WEISS, J.; TRIBE, M. (Ed.). Routledge Handbook of Industry and Development. Abingdon : New York: Routledge, 2016. p. 65-83.

TREGENNA, F. Deindustrialisation: an issue for both developed and developing countries. In: WEISS, J.; TRIBE, M. (Ed.). Routledge Handbook of Industry and 
Development. London: Routledge, 2016. p. 97-115. 